\title{
VALUE DRIVEN DESIGN REVISITED: EMERGING MODELLING CONCEPTS AND APPLICATIONS
}

\author{
Bertoni, Marco (1); Bertoni, Alessandro (1); Murat Hakki, Eres (2) \\ 1: Blekinge Institute of Technology; 2: University of Southampton
}

\begin{abstract}
Extended product warranties, leasing, and pay-per-use schemes are few examples of how manufacturing companies are shifting their focus from selling products to offering "solutions", combining products and services to maximise customer value. The idea of optimising a system towards the best 'value' is both "intuitive and sensible", and processes such as Value Driven Design (VDD), have been proposed to supplement traditional engineering design methodologies. Yet, value-driven initiatives struggle to communicate their benefits and to demonstrate how value models can solve actual problems. The aim of this paper is to shed light on the evolution of the VDD toolbox, mapping research clusters, applications and case studies from the perspective of how much (and how well) recent contributions have answered the five top-level questions of the VDD research agenda published in 2012. The results of the systematic literature review reveal the emergence of innovative modelling constructs, methods, and tools that help VDD in taking a leap forward in supporting organizations and teams in achieving the long-sought objective of designing for 'value'.
\end{abstract}

Keywords: Value Driven Design, Systems Engineering (SE), Design to X, Conceptual design

\section{Contact:}

Bertoni, Marco

Blekinge Institute of Technology

Department of Mechanical Engineering

Sweden

marco.bertoni@bth.se

Cite this article: Bertoni, M., Bertoni, A., Murat Hakki, E. (2019) 'Value Driven Design Revisited: Emerging Modelling Concepts and Applications', in Proceedings of the 22nd International Conference on Engineering Design (ICED19), Delft, The Netherlands, 5-8 August 2019. DOI:10.1017/dsi.2019.247 


\section{INTRODUCTION AND OBJECTIVES}

The realization of solutions that are of high value to customers, improving their satisfaction and consequently profit for the solution provider, is the ultimate goal of engineering design. Extended product warranties and pay-per-use schemes are just few examples of how manufacturing companies are shifting their focus from selling products to offering such 'solutions', which is from design for performance, to design for capability, to (most recently) design for value. Quoting Soban et al. (2012), the idea of optimizing a system towards the best value is both "intuitive and sensible", and several processes, such as Value Driven Design (VDD) (Collopy and Hollingsworth 2011), have been proposed to either supplement or supplant more traditional engineering design methodologies in this quest.

Yet, there are inherent limitations in the way 'value' is identified and used to drive the activities of product design and development, the most intuitive one being the plethora of definitions that characterize the last 50 years of research, from Miles (1967) to recent contributions. At the same time, engineering design research is not fully aware of methods, models and tools to guide organizations and teams in designing for 'value'. The main purpose of this paper is then to shed light on the evolution of the VDD toolbox, with emphasis on modelling concepts and applications. Its objective is to analyse the momentum gained by the VDD movement since the publication of the VDD research agenda by Soban et al., in 2012. The paper maps current applications and case studies from the perspective of how much (and how well) they target the five top-level research questions proposed in the agenda, with the goal of stimulating discussion, developing tools and methodologies that will facilitate the application of VDD and push forward the State-of-the-Art.

\subsection{Systematic review approach}

The investigation of scholarly publications followed a process of systematic review in the SCOPUS database. Initially, the authors developed the 'architecture' for the review, sketching the basic building blocks of the conceptual framework for synthesis. This included the development the search string, which featured the "value driven design", "value centric design" (or VCD, see Brown and Emerenko 2008), "value driven optimization" (Castagne et al., 2009) and "value centric optimization" (Xu et al., 2013) keywords linked by the Boolean operator OR. Both the British and American spelling of the word optimisation were used in the query, resulting in the following search string:

(TITLE-ABS-KEY ("value driven design") OR TITLE-ABS-KEY ("value centric design") OR TITLEABS-KEY ("value centric optimi?ation")) AND DOCTYPE (ar OR cp) AND PUBYEAR > 2011

The search in SCOPUS rendered 118 original research papers, including journal contributions and conference proceedings. Papers were initially filtered on a title and keywords basis, then on an abstract basis. The resulting list of contributions was shortlisted by applying publication-based and content-based criteria. Only contributions classified as journal publications, conference proceedings or book chapters were retained, and only those items focusing on emerging modelling concepts and applications for VDD were included in the final list of papers for review. Snowballing techniques, which were later applied to search for other relevant publications not emerged from the database, rendered 5 additional publications. Eventually, 71 papers were considered relevant for the scope of the review. The analysis stage focused on the identification of relevant contributions for the different research areas of the VDD research agenda (Soban et al., 2011), namely in the 'system', 'stakeholders', 'value function', 'finding the best value' and 'identifying the enablers' macro categories. The analysis was conducted independently by two of the authors, and only those papers fully or partially addressing these specific research questions and sub-questions were retained for further review. Eventually, the results were integrated, and ambiguous categorizations were resolved through discussion between the researchers.

\section{VDD RESEARCH CLUSTERS AND APPLICATIONS}

Figure 1 displays the distribution per year for all 71 contributions. Even though section a) of Figure 1 does not reveal any evident trend, it is noticeable that industrial co-production reaches about one-third of the retrieved publications. 

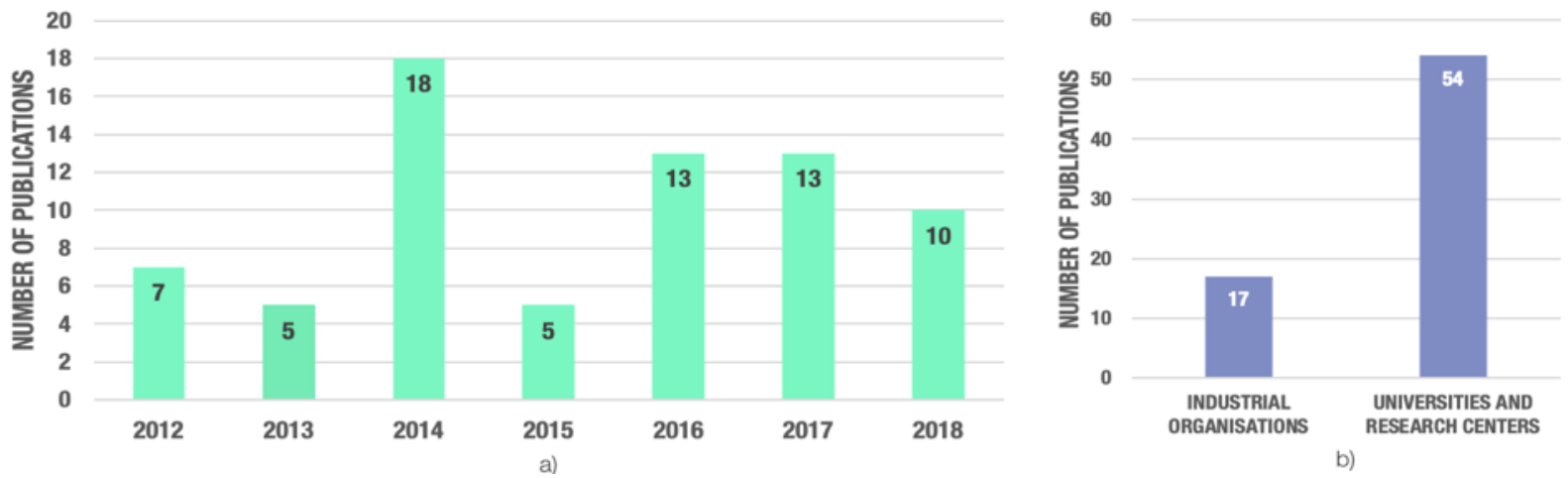

Figure 1. VDD publications distribution a) per year and b) per actor type.

Figure 2 maps the network of academic institutions, research centres and industries active in the dissemination of scientific contributions (responding the above query) between 2012 and 2018. The map features a total of 44 actors (represented as nodes in the network) that have either authored or coauthored publications indexed in SCOPUS. The size of a node is determined by the number of publications authored, which is also shown in the bar below each name for better clarity. The connections between the nodes represents collaborations in co-authoring research works. The width of each lines is proportional to the number of articles written between them. Notably, academic institutions and research centres features light blue nodes, while industrial partners dark blue ones.

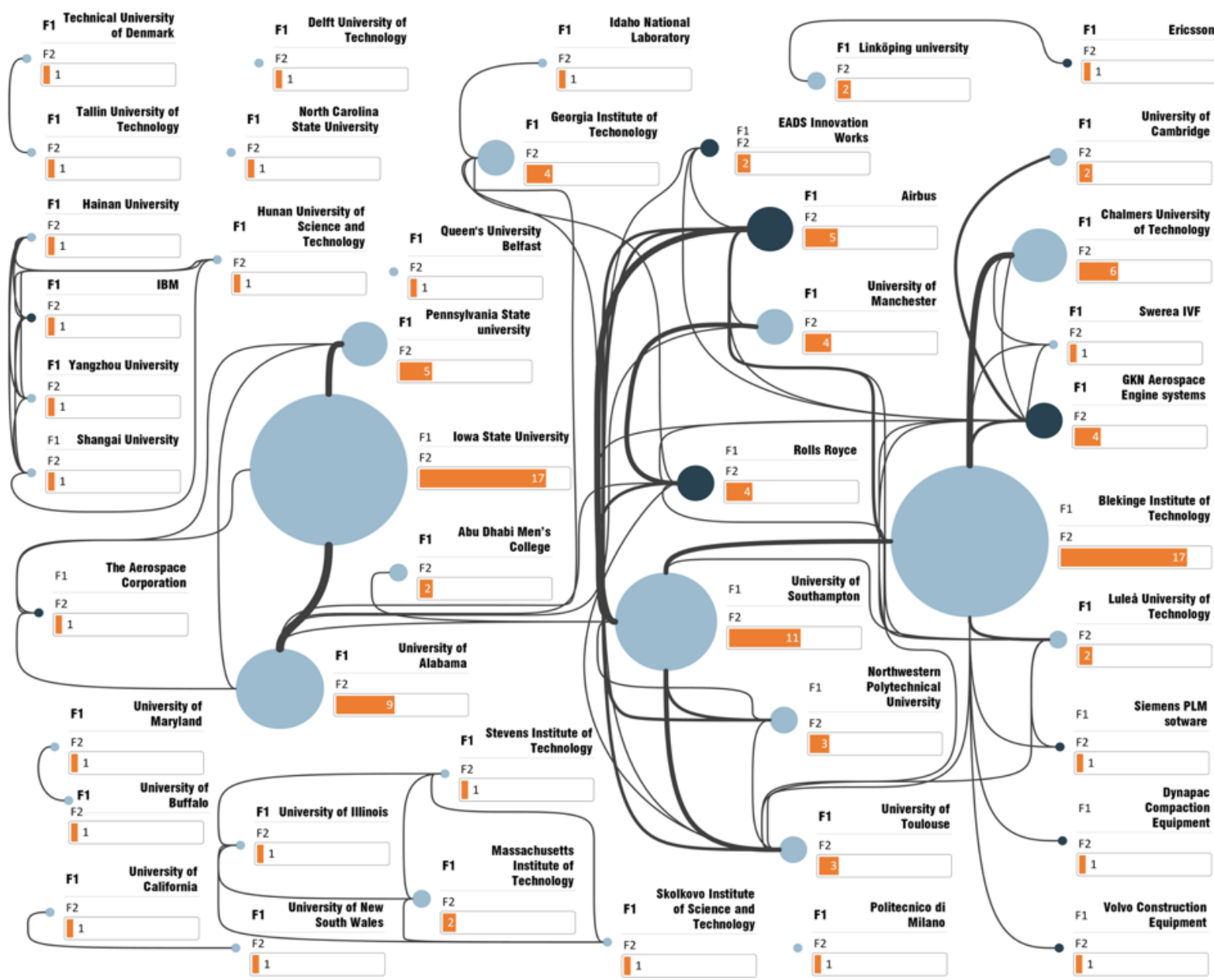

Figure 2. Network map of VDD publications in the period 2012-2018.

Two major research clusters are revealed in the analysis: a first one (centre-left side of the map) features universities and institutions located in the US, with Iowa State University, University of Alabama and Pennsylvania State University being dominant nodes. A second clusters is driven by British, Swedish and French actors, with the University of Southampton, Blekinge Institute of Technology, and Chalmers 
University of Technology featuring the highest number of publications in the analysed timeframe. Notably, the University of Southampton is not only one of the active institutions but also acts a bridge between research conducted on the opposite sides of the Atlantic Ocean.

The application landscape for VDD in the US is dominated by aerospace systems engineering, with great focus on the design of satellite systems (see: Kannan et al., 2017). Airbus, Rolls-Royce and GKN Aerospace Engine Systems are dominant industrial 'nodes', criss-crossing between US and Europe and connecting with several universities and institutions. Several Scandinavian companies operating in the telecom and construction sectors - Ericsson, Volvo Construction Equipment and Dynapac Construction Equipment - have also applied VDD in their engineering design processes. Importantly, recent research features a number of 'testbed' applications (i.e., not seemingly conducted in direct collaboration with industrial manufacturers), which are aimed at demonstrating the applicability of VDD modelling concepts for the design of electric vehicle systems (Topcu and Mesmer, 2018), washing machines (Jung et al., 2017) buildings (Zhuang et al., 2017), and energy systems (Lee et al., 2014; Du et al., 2014).

\section{DEFINING THE ‘SYSTEM’ AND ITS BOUNDARIES}

The first question in the VDD research agenda (Soban et al., 2012) stresses the importance of clearly articulating and establishing the boundaries of the system under consideration, before any design or analysis can take place. The unambiguous definition of the system is of foremost important for any successful attempt to optimize value, hence: "How do you define System Boundaries within a VDD context?" has become a major research topic for the VDD community.

\subsection{The emergence of extended system boundaries}

Most contributions today (Du et al., 2014, Simpson et al., 2017, Papageorgiou, 2016, MacKenzie and $\mathrm{Hu}$ 2018) consider the product being designed (i.e., an aircraft, a satellite system, etc.) to be the 'implicit' boundary of a 'system'. This typically encompasses the physical hardware, including development and manufacturing aspects, together with its operational scenarios and several high-level indicators to account for taxes, discount rates, market size, and more (see Desai et al., 2016). Yet, recent contributions suggest reconsidering this classical definition of 'boundaries' to cope with two main trends shaping the product development discussion in the 2010s: sustainability and servitization. When sustainability and environmental impact are proposed as "fundamental" objectives to refine the value model (such as in Zhang 2013), the definition of 'system' changes to include other relevant aspects of the super-systems (e.g., Papageorgiou 2018). This means that the system boundaries need to expand to include a wider set of stakeholders and, in more extreme cases, the society and the planet at large. In this looser interpretation of boundaries', value models shall support the design team in identifying solutions that do not only maximise customer satisfaction while reducing the providers' cost, but that are also beneficial for both people and environment (Bertoni 2017).

There is also an effort to include a "servitization" perspective and circular economy thinking in the value modelling activity, extending the boundaries of the system to be considered in the VDD exercise (Isaksson et al., 2016). The development of Product Service Systems (PSS) requires the ability to evaluate solutions that combines product/service aspects in radically new mixes (Sakao et al., 2012), and that encompass lifecycle dimensions outside the technical horizon of the engineering team (Bertoni et al., 2016). In a situation where 'value' is no longer determined by the mere performances of the physical hardware, but rather by those of the entire service system, the boundaries of the VDD system must be necessarily extended to cover all servitization aspects that add value to the total solution.

\subsection{The system decomposition dilemma}

The decomposition of a system, either physical or functional, is a cornerstone of VDD and a major concern for engineers and designers. Two competing approaches are observed in literature with regards to the type of architecture needed to describe a system in VDD. Isaksson et al. (2016) illustrates how functional modelling can be used to translate the original design intent to alternative conceptual solutions for an attractive technology that is then targeted for validation. This functional architecture is the critical enabler to identify interrelationships between these critical subsystems, which is another main question in the VDD research agenda. A similar approach is proposed by Panarotto et al. (2018), who describe an Enhanced-Function Means (EF-M) approach to capture the interaction between design solutions through 
the use of an "iw" ('interacts with') link. Simpson et al. (2017) propose, instead, the use of a physical approach when dealing with VDD optimization. In their example, a satellite system is decomposed into physical sub-systems and components along three levels of hierarchy. These subsystems at Level 1 are then decomposed into lower level items, to eventually define 36 design variables (14 continuous and 22 discrete) that describe technology choices associated with each of the subsystems. In this approach, the ability to capture the interplay between levels is critical to explore how different subsystem decompositions contribute to the overall value of the system. Kannan et al. (2017) further explain that aerospace applications shall favour a physical approach for system decomposition because the physics associated with, for instance, a satellite system are inherently coupled.

\section{MODELLING STAKEHOLDERS EXPECTATIONS AND NEEDS}

VDD differs from more traditional design processes mainly in terms of how expectations from the stakeholders are treated and managed in the process to guide design activities. Every value model has a point of view, and its recognition is critical for building the model (Collopy 2009). Hence, to ensure the ultimate and correct value is captured by the system, it is crucial for the design team to be systematically supported in the approach distillation and prioritization of stakeholders' expectations for a given system.

\subsection{The emergence of the value creation strategy construct}

One notion that has become popular in VDD literature in recent years is that of Value Creation Strategy (VCS). This construct was originally proposed by Monceaux and Kossmann (2012) to synthesise the prioritized set of needs that capture the intent of the overall design task and it is designed to facilitate understanding also between different design teams and suppliers. It is designed to facilitate the early stage exchange of relevant value information across the partners in the network, including a list of 'value drivers' with priorities. This allows all participants in the design process to initiate their early conceptual work on a much more relevant basis than what would otherwise be the case. Furthermore, the results of such preliminary investigations can be fed back to the system integrators to provide a feedback on how to update a design in order to add more value. The VCS, by enforcing an early stage feedback loop among all actors in the value chain, does not only answer the problem of distilling and prioritizing the stakeholders' expectations. Its introduction also stimulates search for architectural options that are more novel and radical, and that are not driven by simple incremental improvements of existing platform (e.g. by low weight and high-performance issues such in the aerospace sector). Several recent works in the VDD field (Isaksson et al., 2013, Bertoni et al., 2018, Kiporpous et al., 2014; Panarotto et al., 2018) make use of the VCS to define the nature and characteristics of the value model.

\subsection{The emergence of game theory for multi-actor value optimization}

Extending system boundaries means for VDD engineers to include a wider range of potential stakeholders in their value optimization process. Topcu and Mesmer (2018) illustrate the conflicting nature of stakeholders' expectations in their electric vehicle (EV) example. In their case study, the final customers (i.e., the commercial company and the government) are viewed as having significant influence on EV design. This situation is similar to that described by Zhuang et al. (2017): designers are tasked with the problem of optimizing not only towards the maximization of customer value, but also towards the expectations of the so called 'general public'.

The introduction of game theory has been considered in recent years an important advance in modelling methods for VDD, because it captures interactive effects and local objectives among multiple decisionmakers with conflicting interests. Therefore, value-centric design methodologies have been extended to multi-actor cases by using game-theoretic principles. Grogan et al. (2018) propose a multi-actor surplus value model (SVM) that extends the classical single-actor approach (see: Price et al., 2012). A multi-actor SVM assesses alternative design and strategy decisions considering multiple interactive players in a cooperative vs. non-cooperative scenario, to structure and fill entries in a game-theoretic payoff matrix. Papageorgiou et al. (2018) propose another application of game theory for VDD. The described value assessment methodology consists of a combination of multi-attribute value/utility analysis with the Game Theory and the Analytic Hierarchy Process (AHP). This approach is based on the realization that a noncooperative non-zero-sum game exists between the stakeholders as players. Hence, the identification of the optimal design can only be obtained by identifying the optimal design through the simultaneous employment of the Nash bargaining solution and the Nash equilibrium. 


\section{Defining the VALUE fUNCtion}

Not surprisingly, the main focus of research on value-oriented methodologies in the last 5 years has been the value function, which is the "heart of VDD" in the words of Soban et al. (2012). The literature has mostly tried to propose solutions to the intricate problem of doing 'apples to oranges' trade-offs, combining all relative figures of merit for a system into a single, unifying score.

\subsection{The emergence of profit-seeking functions}

VDD finds its roots in several initiatives promoted in the 2000s by the Defence Advanced Research Projects Agency (DARPA) in the US. This have had a strong influence in the way value models are constructed and populated, because stakeholders from military organizations have very different preferences from profit-driven organizations (Goetzke et al., 2014). This means that operational value functions - which include aspects such as the probability of success for an individual system or a set of systems - have been often prioritized against profit-seeking value functions. More recent applications of VDD to commercial systems design (e.g., Castagne et al., 2009, Cheung et al., 2012) brought back the notion of profit in the VDD models, mainly because, as explained by Kiporous and Isaksson (2014), profit makes the design and optimization of a physical system much more manageable and intuitive for the designers. Net Present Value (NPV) and Surplus Value (SV) are among the most common forms of such functions (e.g., Price et al., 2012, Selva and Crawley 2013). MacKenzie and $\mathrm{Hu}$ (2018), for instance, consider discounted expected profit (or Net Present Value) as the main objective of decision making by a risk-neutral firm. The firm's expected profit is composed of the firm's design cost and the operating profit during the lifetime of the new system. The proposed decision-making model considers attributes such as robustness and rapidity of restoration as means for the firm's fundamental objective of maximizing its profit. Hence, the profit function allows the firm to simultaneously make trade-offs among the cost of designing a more resilient system, the cost of a failed system, and the revenue gained from a functioning system. Yet, there are several exceptions to this general observation, with 'value models' being often interpreted as utility function based on cost and other desirable feature of the system (e.g. reliability, availability, scalability, and changeability). The Value Driven Tradespace Exploration (VOTSE) framework (Jackson et al., 2017) is one of such examples, which proposes the use of a mathematical algorithm to identify the 'most valuable' design from a large number of candidate system concepts at the frontier of the Cost-Reliability tradespace.

\subsection{The emergence of qualitative value models}

Isaksson et al. (2015) shows that the value function is not a static construct in the engineering design process, but rather changes as soon as more information is learned about the system. The Knowledge Value Stream (KVS) - Product Value Stream (PVS) framework (Kennedy et al., 2008) is used to highlight the existence of at least two types of value functions, with different objectives and characteristics. A qualitative value modelling loop in the KVS aims at generating a first assessment of the potential and risk associated to a design concept or technology, filtering potential technology candidates using a broader set of criteria than what happens today in preliminary design. The quantitative value modelling loop in the PVS is triggered by the selection of a product concept from this set.

Qualitative and intangible (see: Papageorgiou 2018) surrogate metrics for value (e.g. novelty, quality, and variety) are acknowledged to fulfil an important function, which is that of including sociological, psychological, and organizational factors in the assessment, something that is not captured by monetary models alone (see: Lee and Paredis 2014). Yet, literature is also aware of the difficulty in adding these metrics together to form a valuable basis for comparing solutions from a value perspective. The quest for a systematic approach to aggregate intangible aspects of value in the engineering decision making process has resulted in several tools that expand and adapt traditional Multi Criteria Decision Making (MCDM) tools to fit the aim of VDD. The Concept Design Analysis (CODA) (Eres et al., 2014) exemplifies the need for expanding traditional Systems Engineering tools, in this case QFD, by introducing non-linear functions - analogous to the Taguchi Loss Functions (Wadsworth 1997) - to capture value in the 'house of quality' in a more realistic and detailed way (Zhang et al., 2014). A similar extension is the EVOKE model proposed by Bertoni et al. (2018), which further expands CODA by introducing the VCS notion to define the priority between the different value attributes. These extensions are justified by need to capture the relationship between value-items and more requirement-oriented features with the highest possible level of granularity. 


\subsection{The emergence of surrogate modelling}

Surrogate modelling is not a new technique in the domain of VDD. Recent contributions (see: Du et al., 2014) demonstrate the application of these techniques to study several key performance aspects for hybrid energy systems. However, the emergence of cross-disciplinarity and 'digitalization' have brought a new meaning to this exercise. The construction of reduced order models is found to be beneficial to reduce simulation time compared to the original high-fidelity models, a very desirable feature during decision gate meetings (Bertoni et al., 2018). Isaksson et al. (2016) shows that VDD is a fundamentally cross-functional activity: the definition of core functional requirements for an aerospace system, for instance, is becoming more and more a matter of gathering and managing multidisciplinary team of engineers, facilitating the knowledge sharing between them and incubating radical ideas and new functions. Panarotto et al. (2018) further shows that the preparation of the inputs for the value assessment activity is a collective and iterative effort among the partners participating in the development project. Robustness and speed of execution becomes of critical importance when working in a cross-functional team setting. It shall be possible to conduct plenty of what-if simulations in a matter of seconds, and their results should be communicated to the team almost instantaneously. Surrogate modelling becomes then a key enabler to support value discussions and negotiations in cross-functional teams, mainly because research have observed that error messages, or even a lag of few seconds during the computation process, might spoil the discussion and negatively impact knowledge sharing (Bertoni et al., 2018). More than an issue of pure computing power, this is a problem of developing efficient schemes on how to produce data for the visualization, and how to manage them to enable a real-time experience when exploring design concepts.

\section{DEFINING ENABLERS FOR VALUE DRIVEN DECISION MAKERS}

The last research area in the VDD agenda focuses on enablers' that facilitate "putting value-driven methodologies into practice" (Soban et al., 2012). These include both decision support tools as well as communication enablers supporting knowledge sharing across all levels of design.

\subsection{The emergence of uncertainty modelling}

NPV and SV functions do not traditionally include uncertainty. The development of methods and models to capture the uncertainty in the behaviour (i.e., value) of the system being designed has therefore attracted the interest of many in the VDD community. One way of introducing uncertainty is to construct a decision tree where the NPVs of each project under a set of plausible scenarios are calculated (see: Selva and Crawley 2013). Each scenario is then assigned a certain probability of occurrence, and the expected NPV is computed as the average of the NPVs in each scenario weighted by the probability of occurrence of the scenarios. More recent works, such as that of MacKenzie and $\mathrm{Hu}$ (2018), propose a time-series simulation method to assess the time-dependent resilience of a component. The method employs a sequential Monte Carlo Simulation (MCS) to generate random samples (or trajectories) of component performance based on adverse condition-dependent degradation rates and restoration models. Similarly, Desai and Hollingsworth (2018) show that by using second-order stochastic dominance it is possible to reduce the risk of incorrect decisions being taken due to the risk aversion of the engineering team. Wang and Kannah (2017) goes a step further in their attempt to quantify uncertainty by borrowing the Gini Coefficient from the field of economics to measure the inequality among values of a frequency distribution. Topcu and Mesmer (2018) further demonstrate how to incorporate uncertainties related to variables and parameters into the design framework using probability density functions (PDF) and MCS. The PDFs represent the expected probabilistic characteristics of the associated variables or parameters, while MCS uses these distributions to determine the PDF of the system attributes (i.e. their uncertainties). A different approach is proposed by Bertoni et al. (2018) with the concept of knowledge maturity. VDD stresses the quantification of information that is seldom precise and exact, hence a mechanism is needed to simultaneously state the degree of certainness of the quantification made. The authors propose then to implement a mechanism that is able to indicate the level to which the engineering team may trust the material entering in the value assessment activity, assisting decision makers in achieving a better understanding of what such uncertainty involves. This concept is also referred as Knowledge Maturity and computes the state of readiness of a knowledge asset used to build a value model using a narrative scale over three dimensions: input, method (tool), and expertise (experience). 


\subsection{The emergence of visual analytics}

Recent research has stressed the role played by visual analytics for VDD. The growing cross-disciplinary of engineering teams asks for enhanced visualization means to display the outcomes of the value modelling activities at decision gates. Parallel Coordinates (Kiporous and Isaksson 2014) have become a popular means to simultaneously display the results of value analysis onto each value dimension in the same plot as the design variables. The main reason for such popularity is that decision makers can work interactively with the data set, and filter out architectures in several ways, either via filters on the parameters or via a graphical plot in 2D where two selected parameters are compared to each other (e.g., Jackson et al., 2017). Simpson et al. (2017) shows a further example of how parallel coordinate plots can be applied to visualize the effect of input parameters on preferred output variables. This visualization approach is often preferred because it provides a good initial view of the system, showing the variability of value for the most important components of each subsystem. Scatter Plots are often used to summarize the results of the value assessment activity along conflicting dimensions for system design, so to more easily communicate tradeoffs and points of maximum value (MacKenzie and $\mathrm{Hu}$ 2018). These are further extended to 3D glyph plots (e.g., Zhang et al., 2013, Simpson et al., 2017) when more conflicting variables are assessed at the same time. They are also used for subsystem-by-subsystem visualization, when the objective is no longer that of merely indicating points of interest, but rather to analyse the relationships between the subsystems (Simpson et al., 2017). The concept of color-coding is further explored by Zhang et al. (2013) to communicate the results of sensitivity analysis conducted on the value modelling results. An approach using color-coded 3D CAD models for value visualization in SIEMENS NX HD3D visual reporting has been also proposed (Bertoni et al., 2014).

\section{DISCUSSION AND CONCLUSIONS}

VDD represents a potential paradigm shift for engineering design. By facilitating the 'apples to oranges' trade-off exercise since an early design phase, it highlights the advantages linked to radical design concepts and can potentially reduce rework caused by local-optimum decisions. In recent years, value models have evolved from the original 'transfer function' described by Keeney (1992) towards more sophisticated formulations, which have become common also outside the aerospace domain. Yet, VDD is struggling to become mainstream within the engineering design community, due to the problem of communicating the benefit of the approach compared to more established and traditional methodologies. Even though several contributions bring forward arguments and 'statistical' data about the intrinsic inefficiency of classical requirements engineering, it is far to be proven that VDD is able to cope with this issue. Therefore, clearer 'grand challenges', together with simpler cases and demonstrators are needed for better communications and dissemination, demonstrating the ability of VDD to solve actual problems - i.e., not being simply another buzzword.

Future work will aim at developing capabilities for benchmarking alternative business models, such as functional agreements like the power-by-the-hour contracts offered by the aero-engine manufacturer Rolls-Royce. Even though several examples are shown on how the expectations of several levels of customers and stakeholders can be brought in during the value modelling activity, the question "value for who?" during this exercise remains and it is even more emphasised when moving from one-sale models to functional results.

Even though the literature review highlights VDD being the main umbrella term today to describe valueoriented methodologies, it is still unclear how other terms such as Value Centric Design and Value Centric Optimization relates to it. Hence, VDD must agree on a common semantic, stressing the consistency of terms and highlighting where methods and tools overlap with those from other communities. Additionally, the relationship between VDD and Multi-Disciplinary Optimization (MDO) should be clarified. Yet, a major limitation of MDO is that it tends to simplify reality to a level that the problem can be solved, but the problem has shifted away from the reality, i.e., the value function in MDO exercises is selected more on the basis of its 'solvability' than 'realism'. Furthermore, the intention of VDD is not that of remove the people from decisions, rather that of 'empowering' or 'enabling' valueoriented decisions, mainly because it is not possible to model all aspects of design.

\section{REFERENCES}

Bertoni, M. (2017), "Introducing Sustainability in Value Models to Support Design Decision Making: A Systematic Review”, Sustainability, Vol. 9 No. 6, p. 994. https://doi.org/10.3390/su9060994 
Bertoni, M., Bertoni, A. and Isaksson, O. (2018), "Evoke: A value-driven concept selection method for early system design", Journal of Systems Science and Systems Engineering, Vol. 27 No. 1, pp. 46-77. https://doi.org/10.1007/s11518-016-5324-2

Bertoni, M., Bertoni, A., Broeze, H., Dubourg, G. and Sandhurst, C. (2014), "Using 3D CAD models for value visualization: An approach with SIEMENS NX HD3D visual reporting", Computer-Aided Design and Applications, Vol. 11 No. 3, pp. 284-294. https://doi.org/10.1080/16864360.2014.863492

Bertoni, A., Bertoni, M., Panarotto, M., Johansson, C. and Larsson, T. C. (2016), "Value-driven product service systems development: Methods and industrial applications", CIRP Journal of Manufacturing Science and Technology, Vol. 15, pp. 42-55. https://doi.org/10.1016/j.cirpj.2016.04.008

Brown, O. and Eremenko, P. (2008), "Application of value-centric design to space architectures: the case of fractionated spacecraft", AIAA SPACE 2008 Conference and Exposition, AIAA SPACE Forum, San Diego, CA, Sep. 9-11 https://doi.org/10.2514/6.2008-7869

Castagne, S., R. Curran and P. Collopy. (2009), "Implementation of Value-Driven Optimisation for the Design of Aircraft Fuselage Panels”, International Journal of Production Economics, Vol. 117, pp. 381-388. https://doi.org/10.1016/j.ijpe.2008.12.005

Cheung, J., Scanlan, J., Wong, J., Forrester, J., Eres, H., Collopy, P., Hollingsworth, P., Wiseall, S. and Briceno, S. (2012), "Application of value-driven design to commercial aeroengine systems", Journal of Aircraft, Vol. 49 No. 3, pp. 688-702. https://doi.org/10.2514/1.C031319

Collopy, P. (2009), “Aerospace System Value Models: A Survey and Observations”, AIAA SPACE 2009 Conference and Exposition AIAA SPACE Forum, Pasadena, California, Sep. 14-17. https://doi.org/10.2514/6.2009-6560

Collopy, P.D. and Hollingsworth, P.M. (2011), "Value-Driven Design”, Journal of Aircraft, Vol. 48 No. 3 , pp. 749-759. https://doi.org/10.2514/1.C000311

Desai, A. A., Hollingsworth, P. M. and Jinks, S. (2018), "Stochastic Aircraft Optimization and Decision Making using a Competitive Value-Driven Design Framework", 2018 Aviation Technology, Integration, and Operations Conference, AIAA AVIATION Forum, Atlanta, GA, June 25-29. https://doi.org/10.2514/6.2018-2869

Desai, A., Hollingsworth, P. and Chinchapatnam, P. (2016), "Identifying the best design for uncertain markets", 30th Congress of the International Council of Aeronautical Science, Daejeon, Korea, September 25-30.

Du, W., Garcia, H. E., Binder, W. R. and Paredis, C. J. (2014), "Value-driven design and sensitivity analysis of hybrid energy systems using surrogate modeling", International Conference on Renewable Energy Research and Application (ICRERA), Milwaukee, WI, Oct. 19-22. https://doi.org/10.1109/ICRERA.2014.7016416

Eres, M. H., Bertoni, M., Kossmann, M. and Scanlan, J. (2014), "Mapping customer needs to engineering characteristics: an aerospace perspective for conceptual design”, Journal of Engineering Design, Vol. 25 No. 1-3, pp. 64-87. https://doi.org/10.1080/09544828.2014.903387

Grogan, P.T., Ho, K., Golkar, A. and de Weck, O.L. (2018), "Multi-actor value modeling for federated systems", IEEE Systems Journal, Vol. 12 No. 2, pp. 1193-1202. https://doi.org/10.1109/JSYST.2016.2626981

Isaksson, O., Bertoni, M., Hallstedt, S. and Lavesson, N. (2015), "Model Based Decision Support for Value and Sustainability in Product Development", 20th International Conference on Engineering Design (ICED), Milan, Italy, Jul. 27-30, The Design Society, pp. 21-30

Isaksson, O., Bertoni, A., Levandowski, C., Müller, J., Wiklund, D. and Johansson, P. B. V. (2016), "Virtual contextual validation of technologies and methods for product development", 14th International Design Conference, Dubrovnink, Croatia, pp. 669-678.

Isaksson O, Kossmann K, Bertoni M, Eres H, Monceaux A, Bertoni A, Wiseall S, Zhang X (2013), "Value Driven Design: A methodology to Link Expectations to Technical Requirements in the Extended Enterprise". INCOSE Symposium 2013, Vol. 23 No. 1, pp. 803-819. https://doi.org/10.1002/j.23345837.2013.tb03055.x

Jackson, C., Qasisar, S.U. and Ryan, M.J. (2017), "Value driven tradespace exploration: A new approach to optimize reliability specification and allocation”, 2017 Annual Reliability and Maintainability Symposium, Orlando, FL, Jan 23-26, pp. 1-7. IEEE. https://doi.org/10.1109/RAM.2017.7889655

Jung, S., Simpson, T. W. and Bloebaum, C. (2017), "Value-Driven Design Using Discipline-Based Decomposition for a Family of Front-Loading Washing Machines”, ASME 2017 International Design Engineering Technical Conferences and Computers and Information in Engineering Conference, Cleveland, OH, Aug 6-9, p. 13 https://doi.org/10.1115/DETC2017-67631

Kannan, H., Mesmer, B.L. and Bloebaum, C.L. (2017), "Increased System Consistency Through Incorporation of Coupling in Value-Based Systems Engineering”, Systems Engineering, Vol. 20 No. 1, pp. 21-44. https://doi.org/10.1002/sys.21377

Keeney, R.L (1992), Value-focused thinking: A path to creative decision making. Harvard University, Cambridge, MA.

Kennedy, M., Harmon, K., Minnock, E. (2008), Ready, Set, Dominate: Implement Toyota's Set-Based Learning for Developing Products and Nobody Can Catch You, The Oaklea Press. 
Kipouros, T. and Isaksson, O. (2014), "Integrating value assessment into the computational engineering design cycle", 1st International Conference on Engineering and Applied Sciences Optimization, Kos, Greece, Jun 4-6, pp. 2446-2455. https://doi.org/10.1007/978-3-319-18320-6

Lee, B.D., Binder, W.R. and Paredis, C.J. (2014), "A systematic method for specifying effective value models", Procedia Computer Science, Vol. 28, pp. 228-236. https://doi.org/10.1016/j.procs.2014.03.029

Lee, B.D. and Paredis, C.J. (2014), "A conceptual framework for value-driven design and systems engineering”, Procedia CIRP, Vol. 21, pp. 10-17. https://doi.org/10.1016/j.procir.2014.06.147

MacKenzie, C.A. and Hu, C. (2018), "Decision Making under Uncertainty for Design of Resilient Engineered Systems", Reliability Engineering and System Safety, In Press, https://doi.org/10.1016/j.ress.2018.05.020

Miles, L. D. (1967), Value engineering. Verlag Moderne Industrie.

Monceaux, A. and Kossmann, M. (2012), "Towards a Value-Driven Design Methodology-Enhancing Traditional Requirements Management Within the Extended Enterprise", INCOSE International Symposium, Vol. 22 No. 1, pp. 910-925. https://doi.org/10.1002/j.2334-5837.2012.tb01379.x

Panarotto, M., Isaksson, O. and Asp, L. (2018), “Assessing the value of radical technology alternatives at system level”, 15th International Design Conference. Dubrovnik, Croatia, May 21-25, pp. 633-642. https://doi.org/10.21278/idc.2018.0398

Papageorgiou, E., Eres, M.H. and Scanlan, J. (2016), "Value modelling for multi-stakeholder and multi-objective optimisation in engineering design”, Journal of Engineering Design, Vol. 27 No. 10, pp. 697-724. https://doi.org/10.1080/09544828.2016.1214693

Papageorgiou, E. (2018), "Development and application of a value driven design assessment framework to an unmanned air system design", Advances in Science and Engineering Technology International Conferences, Abu Dhabi, UAE, Feb 5-Apr 6, pp. 1-6. https://doi.org/10.1109/ICASET.2018.8376805

Price, M, Soban, D., Mullan, C., Butterfield, J. and Murphy, A. (2012), "A novel method to enable trade-offs across the whole product life of an aircraft using Value Driven Design", Journal of Aerospace Operations, Vol. 1, pp. 359-375. https://doi.org/10.3233/AOP-120028

Sakao, T. and Lindahl, M. (2012), "A value based evaluation method for Product/Service System using design information”, CIRP Annals-Manufacturing Technology, Vol. 61 No. 1, pp. 51-54. https://doi.org/10.1016/j.cirp.2012.03.108

Selva, D. and Crawley, E. F. (2013), "VASSAR: Value assessment of system architectures using rules", IEEE Aerospace Conference, BigSky, MT, March 3-10, pp. 1-21. https://doi.org/10.1109/AERO.2013.6496936

Simpson, T.W., Miller, S., Tibor, E.B., Yukish, M.A., Stump, G., Kannan, H., Mesmer, B. Winer E.H. and Bloebaum, C.L. (2017), “Adding Value to Trade Space Exploration When Designing Complex Engineered Systems”, Systems Engineering, Vol. 20 No. 2, pp. 131-146. https://doi.org/10.1002/sys.21384

Soban, D., Hollingsworth, P., Price, M. (2011), "Defining a research agenda in Value Driven Design: Questions that need to be asked", Journal of Aerospace Operations, Vol. 1 No. 4, pp. 329-342, https://doi.org/10.3233/AOP-120026

Topcu, T. G. and Mesmer, B. L. (2018), "Incorporating end-user models and associated uncertainties to investigate multiple stakeholder preferences in system design", Research in Engineering Design, Vol. 29 No. 3, pp. 411-431. https://doi.org/10.1007/s00163-017-0276-1

Wadsworth, H.M. (1997), Handbook of statistical methods for engineers and scientists (2nd ed.), McGraw-Hill Professional, New York.

Xu, M., Wang, J., Zhang, A. and Liu, S. (2013), "Probabilistic value-centric optimization design for fractionated spacecrafts based on unscented transformation", Mathematical Problems in Engineering, Vol. 2013, p. 10 http://dx.doi.org/10.1155/2013/132920

Wang, M., Kannan, H. and Bloebaum, C.L. (2017), "Value Driven Optimization in an uncertain marketplace and quantifying uncertainty with the Gini coefficient", 9th AIAA Non-Deterministic Approaches Conference, AIAA SciTech Forum, Grapevine, Texas, Jan 9-13, https://doi.org/10.2514/6.2017-1953

Zhang, X., Auriol, G., Eres, H. and Baron, C. (2013), "A prescriptive approach to qualify and quantify customer value for value-based requirements engineering", International Journal of Computer Integrated Manufacturing, Vol. 26 No. 4, pp. 327-345. https://doi.org/10.1080/0951192X.2012.717718

Zhang, X., Tong, S., Eres, M.H., Kossmann, M. and Wang, K. (2014), “A value-focused approach for establishing requirements' specification of commercial aircraft”, Journal of Aerospace Engineering, Vol. 228 No. 11, pp. 2033-2044. https://doi.org/10.1177/0954410013516302

Zhuang, J., Hu, M. and Mousapour, F. (2017), "Value-Driven Design process: A systematic decision-making framework considering different attribute preferences from multiple stakeholders”, Journal of Solar Energy Engineering, Vol. 139 No. 2, p. 6, https://doi.org/10.1115/1.4035059.

\section{ACKNOWLEDGMENTS}

The research leading to these results has received financial support by the Swedish Knowledge and Competence Development Foundation (Stiftelsen för kunskaps- och kompetensutveckling) through the Model Driven Development and Decision Support research profile at Blekinge Institute of Technology. 